\title{
Evaluation of self-esteem in cancer patients undergoing chemotherapy treatment $^{1}$
}

\author{
Marilia Aparecida Carvalho Leite ${ }^{2}$ \\ Denismar Alves Nogueira ${ }^{3}$ \\ Fábio de Souza Terra ${ }^{4}$
}

Objective: to evaluate the self-esteem of cancer patients undergoing chemotherapy. Method: descriptive analytical cross-sectional study with a quantitative approach. Around 156 patients that attended an oncology unit of a mid-sized hospital participated in the study. Results: we found a higher frequency of patients with high self-esteem, but some of them showed average or low self-esteem. The scale showed a Cronbach's alpha value of 0.746 , by considering its acceptable internal consistency for the evaluated items. No independent variables showed significant associations with self-esteem. Conclusion: the cancer patients evaluated have presented high self-esteem; thus, it becomes crucial for nursing to plan the assistance of patients undergoing chemotherapy treatments, which enables actions and strategies that meet their physical and psychosocial conditions, aiming to maintain and rehabilitate these people's emotional aspects.

Descriptors: Self Concept; Neoplasms; Drug Therapy; Oncology Nursing.

\footnotetext{
1 Paper extracted from master's thesis "Avaliação da autoestima em pacientes oncológicos submetidos ao tratamento quimioterápico", presented to Universidade Federal de Alfenas, Alfenas, MG, Brazil.

2 MSc, RN, Hospital Universitário Alzira Velano, Alfenas, MG, Brazil.

${ }^{3} \mathrm{PhD}$, Adjunct Professor, Instituto de Ciências Exatas, Universidade Federal de Alfenas, Alfenas, MG, Brazil.

${ }^{4}$ PhD, Adjunct Professor, Escola de Enfermagem, Universidade Federal de Alfenas, Alfenas, MG, Brazil.
}

Corresponding Author:

Marilia Aparecida Carvalho Leite Universidade Federal de Alfenas Rua Gabriel Monteiro da Silva, 700 Centro

CEP: 37130-000, Alfenas, MG, Brasil

E-mail: Iyla.leite@hotmail.com
Copyright () 2015 Revista Latino-Americana de Enfermagem This is an Open Access article distributed under the terms of the Creative Commons Attribution Non-Commercial License (CC BY-NC).

This license lets others distribute, remix, tweak, and build upon your work non-commercially, and although their new works must also acknowledge you and be non-commercial, they don't have to license their derivative works on the same terms. 


\section{Introduction}

Cancer is a serious public health problem not only in Brazil but also worldwide, worsening in recent years because of population aging in developing countries such as Brazil. This disease is different from other chronic diseases since its pathology can lead to deformities, pain and mutilation, also causing great psychological impact and negative feelings from the time of diagnosis ${ }^{(1-2)}$.

The last two decades witnessed a considerable progress in the diagnosis and treatment of cancer. The main forms of treating cancer are: surgery, radiation therapy, chemotherapy, hormone therapy, immunotherapy, and combined therapy that may be gather all forms of treating cancer(3).

The use of antineoplasic chemotherapy has become one of the most promising ways to fight cancer. However, several factors must be taken into account during its planning, such as the patient's age, nutritional status, renal, hepatic and pulmonary functions, presence or absence of infection, tumor type, presence of metastases, and patient's life condition $^{(4-5)}$.

It is worth highlighting that patients may have their psychological balance threatened by necessary changes in the course of the disease and of treatments, which includes changes in self-esteem. The adaptation or the psychosocial adjustment to cancer is a process in which people try to deal with their suffering, solve specific problems, and take control over events triggered by the disease(6).

Low self-esteem can be defined as the absence of positive feelings individuals have for themselves, being of great relevance in their relationships with others, also encouraging their performance in relation to their goals(7).

Regarding cancer treatment, patients may face changes in physical appearance, barriers to routine activities that sometimes are added to chemotherapy, the stigma of the disease, the difficulty of addressing the treatment and side effects, and readaptation after treatment. These patients may have psychological problems such as changes in their self-esteem once their perception on body image is related to this new life condition ${ }^{(8)}$.

Given the high incidence of people with cancer, we not only must be aware of early diagnosis and appropriate treatment, but also of the individuals' perception on life to ensure a good quality of life index. It is also necessary to maintain their emotional state healthy despite all shock ${ }^{(8)}$.

Thus, self-esteem, responsible for instigating approval attitudes regarding the ability and the value that individuals have of themselves, depends on their emotional states, being also related to confidence level(7).

We justify the performance of this study by considering all that was previously pointed out and also the small number of studies on the self-esteem of cancer patients undergoing chemotherapy, since we want to sensitize health workers in relation to issues involving the assistance of patients with cancer. This way, it will be possible to improve the quality of the relationship professional/patient/family/institution, to ensure greater adhesion of these patients to treatment, to contribute to the development of strategies that guarantee humanization and assistance completeness, and to improve the self-esteem of patients with cancer undergoing chemotherapy treatment, as well as the interaction between patients/nursing staff.

We decided to conduct this study aiming to evaluate the self-esteem of patients with cancer undergoing chemotherapy in a city in the southern region of the state of Minas Gerais, Brazil.

\section{Method}

This is a descriptive analytical cross-sectional study with a quantitative approach developed in an oncology unit of a mid-sized general hospital located in a city in the southern region of the state of Minas Gerais, Brazil. There were approximately 225 patients in chemotherapy treatment, while others were only being monitored.

Through random sampling, sample calculation has determined a sample of 142 patients. Data was collected from 156 patients who attended the oncology service of the hospital in chemotherapy treatment, composing the final sample of this study.

Data collection occurred from January to May of 2013. For this step, we used a semi-structured questionnaire with sociodemographic variables concerning the treatment and patients' way of life. This instrument has undergone a refining process through the evaluation of five judges: three experts in oncology, one in self-esteem, and one in the construction and validation of research instruments. Later, it underwent a pilot test to check the understanding of the issues by the subjects and the need for adequate vocabulary, with 10 patients of the same study population. We 
highlight that the individuals who participated in this process were not discarded from the final sample, since individuals apparently had no difficulties while answering it, not being necessary any modifications in the instrument during this step.

For the evaluation of self-esteem, we used the Rosenberg Self-Esteem Scale. The original instrument, in English, was developed by Rosenberg, in 1965, being translated and validated for Portuguese in 2001(9).

This is a Likert-type scale of 4 points, containing 10 objective items to evaluate self-esteem through a single dimension, considering that 5 of these evaluate the individuals' positive feelings about themselves and 5 evaluate negative feelings. By adding the scoring obtained through the evaluation of 10 sentences, we calculated the score to total a single value for the scale. The possible range for this scale is from 10 (10 items multiplied by the value 1 ) to 40 (10 items multiplied by the value 4$)^{(9)}$.

The classification of self-esteem is defined by the following scale: high self-esteem (satisfactory), scores over 30 points; average, scores between 20 and 30 points; and low (unsatisfactory) score less than 20 points $^{(9)}$.

This study was approved by the Committee of Ethics in Research in Humans of the Federal University of Alfenas (UNIFAL-MG), protocol 91928/2012. First, we asked authorization to the administration of the institution where the study was carried out, as well as the signature of the free and informed consent form by the participants of the survey. Anonymity and the right of withdrawal at any stage of the study were guaranteed according to Resolution 466/2012 that deals with Research Involving humans(10).

We used the MS-Excel spreadsheet, version 2010, to prepare a twice typed database. Then, for the statistical, descriptive, and inferential analysis of data, we used the software Statistical Package for Social Science (SPSS), version 17.0.

We used the Cronbach's alpha coefficient to evaluate the reliability of the Rosenberg Self-Esteem Scale and its internal consistency. For the bivariate analysis of independent variables with self-esteem measures, we used the Chi-square test or the Fisher's exact test.

In this study, we adopted a significance level of $5 \%$, that is, the data were statistically significant for $p<0.05$ and, by the end of the analyses, we presented the data in tables with absolute and percentage values and numerical variables with descriptive statistics.

\section{Results}

The total sample presented a higher frequency of male patients with age between 51 and 60 years old (51.9\%, average of 61$)$, married or living with a partner (64.1\%), with 1 to 5 children (71.8\%, average of 2$)$, catholics $(80.8 \%)$, retired or pensioners $(57.0 \%)$, lived in a house they owned (85.9\%), with monthly household income between 651 to 1,200 reais (58.3\%, average of 800$)$, having completed elementary school $(61.6 \%)$, residents of municipalities close to Alfenas, state of Minas Gerais (74.4\%), sedentary (75.6\%), nonsmokers $(80.1 \%)$ - however, smokers claimed to have smoked up to 10 cigarettes per day $(77.4 \%$, average of 4). Ex-smokers (57.6\%) have smoked for a period of 10 to 20 years (55.6\%, average of 19.50$)$ and quit smoking 10 years ago (45.8\%, median 13$)$, not consumers of alcoholic beverages (60.9\%), and those who reported consuming alcohol were classified as light users (used alcohol in the past month but the consumption was less than once a week), and all of them (100.0\%) reported to have been attended by the Brazilian Unified Health System (SUS).

Belonging to variable of type cancer, the category "other" (peritoneum, parotid gland, mouth, prostate, larynx, skin, leukemia, testicles, lymphatic, ovary, Hodking and non Hodking lymphoma, liver, pancreas, brain, bladder, and urethra) obtained, among all surveyed individuals, a percentage of 32.1. As for the stage of the disease, the category non-informed had the higher frequency among participants (42.3\%). We highlight that the stages 3 and 4 represent $37.2 \%$ of the total sample (Table 1 ).

Concerning the time of the current cancer diagnosis, the surveyed people reported having received the diagnosis for up to 6 months (53.2\%, average of $6)$. Regarding the duration of chemotherapy, the category "up to 6 months" was also prominent among the participants $(61.5 \%$, average of 5$)$. The category "up to 6 sessions of chemotherapy", belonging to the chemotherapy sessions variable, was cited by most of the interviewed people (54.5\%, average of 5) (Table 2).

Regarding the variable "other treatment besides chemotherapy", $51.3 \%$ of patients claimed not having done any other therapy. However, for those who had had other therapies, surgery presented greater prominence $(52.6 \%)$. As for cancer in other organs, the sample showed "no" for $75.0 \%$ of cases. However, we noted that for those patients who have already had cancer in other organs, there was a higher frequency in the prostate category, with percentage of 34.2 (Table 3). 
Table 1 - Distribution of cancer patients in chemotherapy treatment consistent to variables of cancer type and stage. Alfenas, state of Minas Gerais, Brazil, 2013

\begin{tabular}{lcc}
\hline \multicolumn{1}{c}{ Variables } & f & $\%$ \\
\hline Type of cancer & 50 & 32.1 \\
Other & 31 & 19.9 \\
Breast & 22 & 14.1 \\
Intestine & 18 & 11.5 \\
Bone & 13 & 8.3 \\
Lungs & 8 & 5.1 \\
Uterus & 7 & 4.5 \\
Stomach & 7 & 4.5 \\
Esophagus & 156 & 100.0 \\
Total & & \\
Stage & 1 & 0.6 \\
Stage 0 & 3 & 2.0 \\
Stage 1 & 28 & 17.9 \\
Stage 2 & 39 & 25.0 \\
Stage 3 & 19 & 12.2 \\
Stage 4 & 66 & 42.3 \\
Not informed & 156 & 100.0 \\
Total & & \\
\hline & & \\
\hline
\end{tabular}

Table 2 - Distribution of cancer patients in chemotherapy treatment according to the variables time of current cancer diagnosis, duration of chemotherapy, and number of chemotherapy sessions. Alfenas, state of Minas Gerais, Brazil, 2013

\begin{tabular}{|c|c|c|}
\hline Variables & f & $\%$ \\
\hline \multicolumn{3}{|c|}{ Time of current cancer diagnosis } \\
\hline Up to 6 months & 83 & 53.2 \\
\hline 7 to 12 months & 49 & 31.4 \\
\hline 13 to 18 months & 10 & 6.5 \\
\hline 19 to 24 months & 13 & 8.3 \\
\hline Over than 24 months & 1 & 0.6 \\
\hline Total & 156 & 100.0 \\
\hline \multicolumn{3}{|l|}{ Duration of chemotherapy } \\
\hline Up to 6 months & 96 & 61.5 \\
\hline 7 to 12 months & 45 & 28.8 \\
\hline 13 to 18 months & 10 & 6.4 \\
\hline 19 to 24 months & 5 & 3.3 \\
\hline Total & 156 & 100.0 \\
\hline \multicolumn{3}{|l|}{ Sessions of chemotherapy } \\
\hline Up to 6 sessions & 85 & 54.5 \\
\hline 7 to 12 sessions & 56 & 35.9 \\
\hline 13 to 18 sessions & 9 & 5.8 \\
\hline 19 to 24 sessions & 6 & 3.8 \\
\hline Total & 156 & 100.0 \\
\hline
\end{tabular}

Table 3 - Distribution of cancer patients in chemotherapy treatment equivalent to the variables that follow other treatments besides chemotherapy (treatment, other types of cancer, and location). Alfenas, state of Minas Gerais, Brazil, 2013

\begin{tabular}{lcc}
\hline \multicolumn{1}{c}{ Variables } & f & $\%$ \\
\hline Other treatments besides chemotherapy & 76 & 48.7 \\
Yes & 80 & 51.3 \\
No & 156 & 100.0 \\
Total & & \\
Type of treatment ${ }^{\star}$ & 40 & 52.6 \\
Surgery & 23 & 30.3 \\
Radiotherapy & 13 & 17.1 \\
Surgery/radiotherapy & 76 & 100.0 \\
Total & & \\
Cancer in other organs & 38 & 25.0 \\
Yes & 117 & 75.0 \\
No & 156 & 100.0 \\
Total & & \\
Location of cancer & \\
Prostate & 13 & 34.2 \\
Breast & 10 & 26.3 \\
Other & 9 & 21.1 \\
Intestine & 4 & 10.5 \\
Lungs & 2 & 5.3 \\
Total & 38 & 100.0 \\
\hline
\end{tabular}

* Only those patients who did other treatment besides chemotherapy + Only those patients who have had cancer in other locations

There was no presence of chronic diseases for $51.9 \%$ of patients. However, most of those who declared to hold some chronic disease $(48.1 \%)$ featured it in an unique way ( $85.3 \%)$. The most frequent disease among participants was high blood pressure with 100\%; but it is worth highlighting the other diseases mentioned by participants, such as diabetes mellitus, chronic obstructive pulmonary disease, hyperthyroidism, hypothyroidism, cysticercosis, and the Barrett's esophagus.

Of the total sample, $51.9 \%$ of the individuals interviewed claimed not to take medicines of continuous use. However, most of those who have undertaken the use of drugs on a daily basis $(48.1 \%)$, have used it in an unique way $(85.3 \%)$. The most used pharmacological group was antihypertensives (100.0\%), followed by hypoglycemic medications, thyroid hormones, bronchodilators, anticonvulsants, antacid and antiulcer medications.

In the variable "milestone event in life", 57.7 percent of participants denied the occurrence of such event. However, of those patients who have 
undergone a milestone event in the last year (42.3\%), the most cited was loss or death of loved ones (with $39 \%$ of answers), followed by the birth of children or grandchildren (27.2\%). Other landmark events also cited by the population under study and that deserve to be mentioned were: celebrations ( $21.2 \%)$, diagnosis of disease in loved ones $(4.5 \%)$, separation from partner or family members $(3 \%)$, and the arrest of family members (3\%).

To the internal consistency of the assessment instrument used, the Rosenberg self-esteem scale, the internal Alpha Cronbach's coefficient was applied with a value of 0.746 . Thus, internal consistency ended up being good and acceptable for the items assessed and correlated with each other, indicating homogeneity.

Concerning the classification of self-esteem, we saw that most of the sample comprises patients with high self-esteem $(70.5 \%)$, followed by patients with average self-esteem (28.2\%), and by the ones considered of low self-esteem (1.3\%) (Table 4 ).

Table 4 - Distribution of cancer patients in chemotherapy treatment according to the classification of self-esteem based on cut-off points. Alfenas, state of Minas Gerais, Brazil, 2013

\begin{tabular}{lcc}
\hline \multicolumn{1}{c}{ Classification of self-esteem } & $\mathbf{f}$ & $\%$ \\
\hline High self-esteem & 110 & 70.5 \\
Average self-esteem & 44 & 28.2 \\
Low self-esteem & 2 & 1.3 \\
Total & 156 & 100.0 \\
\hline
\end{tabular}

We identified in this study that none of the following variables showed significant associations with the measure of self-esteem: gender ( $p=0.172)$, age group ( $p=0.549)$, marital status ( $p=0.363)$, number of children ( $p=0.344)$, monthly household income $(p=0.430)$, education ( $p=0.777)$, occupation ( $p=$ $0.067)$, religious belief $(p=0.160)$, exercise practice $(p=0.994)$, smoking $(p=0.777)$, alcoholic beverages consumption ( $p=0.413)$, cancer type ( $p=0.432)$, disease stage ( $p=0.956)$, time for cancer diagnosis $(p=0.853)$, duration of chemotherapy treatment $(p=$ 0.803 ), number of chemotherapy sessions ( $p=0.708)$, other types of cancer treatment besides chemotherapy $(p=0.836)$, the presence of cancer in other organs ( $p$ $=0.839)$, the presence of chronic diseases $(p=0.457)$, continuous use of medicines ( $p=0.457$ ), and milestone events in life $(p=0.585)$.

\section{Discussion}

Self-esteem is related to the way people see themselves. It may present stable characteristics as well as others considered flexible and adaptive. Thus, people's self-concept may experience momentary changes as, for example, when individuals compare themselves to extremely successful people. With that, it will be possible to feel certain contrast that will inevitably be translated to the reduction or the increase of selfesteem ${ }^{(11)}$.

In a research carried out with 48 women who went through breast cancer surgeries to analyze self-esteem, the authors found that most women (54.1\%) showed high self-esteem ${ }^{(12)}$, accordingly with the findings of this study, which presented higher frequency of patients with high self-esteem.

It is worth mentioning that people with high self-esteem feel confident and appreciated, present positive feelings towards themselves, believe in their own competence, and feel capable of dealing with the imposed challenges and to adapt themselves to different situations. In this way, when people undergoing chemotherapy treatment present high self-esteem, it will be possible for them to see life in another way and, consequently, to face the disease and the treatment differently from patients with low self-esteem ${ }^{(12)}$.

It is relevant to point out that the professional occupation is closely related to the overall assessment individuals make of themselves, which may contribute to increases in self-esteem, i.e., professional dissatisfaction as well as the feeling of incompetence and dependency can affect self-esteem. In this condition, most of the assessed patients were retired or pensioners ${ }^{(13)}$.

Regarding religious belief, another research with the same population characteristics of this study presented 101 catholic participants (86\%) among cancer patients undergoing chemotherapy treatment, meeting the results of this study, in which there was a predominance of Catholicism.

When self-esteem is threatened by a negative event, such as presence of chronic diseases like cancer, individuals may develop increases in the levels of anxiety, since they start to look for alternatives to solve 
the situation. In many cases, these ways are inadequate or harmful to health, such as the consumption of alcohol. The adoption of health-related behaviors has been linked to subjects' dissatisfaction about themselves, with tendencies of adherence to smoking. Thus, it is important to assess the consumption of cigarettes and alcohol by cancer patients undergoing chemotherapy to work together with them and prevent the worsening of their health state ${ }^{(15-16)}$.

There is no doubt that the diagnosis of cancer and its treatments affect negatively the image that patients have of their own bodies, resulting in affective disorders and changes in self-esteem. A type of neoplasm that can cause changes in women's body image is breast cancer. A study with 72 women showed that there are several factors between the impact of breast cancer and its treatment on the self-esteem of patients. Most of these are based on patients' age, on the disease's stage of evolution as well as on treatment types adopted against cancer. However, neither the education level, nor the marital status or the type of breast surgery were associated with the selfesteem expressed by patients, being only a positive relationship between the level of self-esteem and the general perception about the quality of life $\mathrm{e}^{(17)}$.

The experience of diagnosis is singular to each individual. However, the feelings of anguish, fear, worry, and anxiety follow cancer patients from diagnosis until the end of the treatment ${ }^{(6)}$.

According to the data of this study, regarding low or average self-esteem and the frequency of individuals who had had other treatments in addition to chemotherapy, it is important to highlight surgery, which is required in almost all cases, causing changes in the self-concept and body image of patients that face it, once surgery is seen as an aggressive and disturbing method, triggering emotional changes such as anxiety, irritation, uncertainty, and other conflicts. The lack of information on pain and physical limitations in the postoperative period are factors that can aggravate the emotional and social conflicts experienced by patients(12).

Through these surveys, it is important to highlight the relevance of nursing in the identification of the needs presented by patients who have gone or will go through surgery, as well as other treatments besides chemotherapy. A viable proposal would be the formation of groups focused on supporting, maintaining and/or restoring the self-esteem of these patients, once the physical and psychosocial rehabilitation continues by the end of the treatment ${ }^{(12)}$.

We also noted that the low level of social confrontation, as well as the ability to solve problems in patients with cancer, influences the way they see themselves, interfering directly in their expectations and, therefore, leading to low self-esteem. When it comes to the frequency of participants of this study that went through a milestone event in life and self-esteem, it is said that when that event is the death of a loved one (the most cited milestone event), sometimes family members make use of religious help to understand the situation, and to obtain an explanation for the inevitable while searching for support(7-18).

In this way, the death of a loved one can come tied up to a rupture of well-being, a condition that affects work routine, social and familiar life, leading to changes in the psychological state such as in self-esteem. With that, professionals, including the ones from nursing, need to carry out a careful and extensive assessment, not only focused on clinical conditions, i.e., symptoms and complaints, but in the whole biopsychosocial aspect of individuals ${ }^{(19)}$.

\section{Conclusion}

We concluded that the cancer patients assessed in this study presented high self-esteem, considering some of them also presented average self-esteem or low self-esteem. In this way, addressing self-esteem in cancer patients undergoing chemotherapy treatment is complex, since it involves particular characteristics of each individual, which affects the way of dealing with the disease and the treatment. What becomes a great challenge once the knowledge produced on this subject, and attached to this population, is restricted to the promotion of more insightful understanding.

This study presented limitations regarding the research design that did not allow better establishment of the findings cause/effect relationship. However, we assumed the importance of this research to describe the populations' characteristics and the possible association between independent and dependent variables, even though we did not find associations between independent variables and the measurement of self-esteem in this study. 
Another factor considered limiting was the size of the sample that did not allow severe statistical analysis of variables that may be associated with the subjects' level of self-esteem. Finally, the third limitation is related to the difficulty in collecting data for the variable "disease stage", since many patients did not know the stage they were, and also considering that such information was often ignored in most medical records.

Through these results, we infer the necessity of developing longitudinal studies that aim to evaluate these patients' self-esteem in different stages of chemotherapy (by the beginning, the middle, and by the end of it).

Therefore, nursing should promote the involvement of strategies and actions that may assist its work in the maintenance of self-esteem of patients undergoing chemotherapy, and support those who need to be assisted, since the psychosocial rehabilitation continues after the period of diagnosis, as well as by the end of the treatment.

\section{References}

1. Nakashima JP, Koifman RJ, Koifman S. Incidência de câncer na Amazônia ocidental: estimativa de base populacional de Rio Branco, Acre, Brasil, 2007-2009. Cad Saúde Pública. 2012;28(11):2125-32.

2. Salci MA, Marcon SS. Itinerário percorrido pelas mulheres na descoberta do câncer. Esc Anna Nery. 2009;13(3):558-66.

3. Soares EM, Silva SR. Perfil de pacientes com câncer ginecológico em tratamento quimioterápico. Rev Bras Enferm. 2010;63(4):517-22.

4. Nicolussi AC, Sawada NO. Qualidade de vida de pacientes com câncer colorretal em terapia adjuvante. Acta Paul Enferm. 2009;22(2):151-61.

5. Jorge LLR, Silva SR. Evaluation of the Quality of Life of Gynecological Cancer Patients Submitted to Antineoplastic Chemotherapy. Rev. Latino-Am. Enfermagem. 2010;18(5):849-55.

6. Souza JR, Araújo TCCF. Eficácia terapêutica de intervenção em grupo psicoeducacional: um estudo exploratório em oncologia. Estud Psicol. 2010;27(2):187-96.

7. Garzon OE, Salazar, LPM, Barrero JAC, Chavarro AS, Toro GIC, Vernaza MBG. Relación entre las estrategias de afrontamiento, ansiedad, depresión y autoestima, en un grupo de adultos con diagnóstico de cáncer. Psychol Av Discip. 2014;8(1):77-83.

8. Bertan FC, Castro EK. Quality of Life, Anxiety and Depressions Indicators and Sexual Satisfaction in Adult Patients with Cancer. Rev Salud Soc. 2010;1(2):76-88.

9. Dini GM, Quaresma MR, Ferreira LM. Adaptação cultural e validação da versão brasileira da Escala de Autoestima de Rosenberg. Rev Soc Bras Cir Plást. 2004;19(1):41-2.

10. Ministério da Saúde (BR). Conselho Nacional de Saúde. Comissão Nacional de Ética em Pesquisa. Resolução No 466 de 12 de dezembro de 2012: aprova as diretrizes e normas regulamentadoras de pesquisas envolvendo seres humanos. Brasília: Ministério da Saúde; 2012.

11. Ramos M. Adaptação para uma população de estudantes universitários portugueses da escala de autoestima de estado de Heatherton e Policy. Psicologia. 2014;28(1):32-8.

12. Gomes NS, Silva SR. Avaliação da autoestima de mulheres submetidas à cirurgia oncológica mamária. Texto Contexto Enferm. 2013;22(3):509-16.

13. Peixoto F, Almeida LS. Self-concept, Self-esteem and Academic Achievement: Strategies for Maintaining Selfesteem in Students Experiencing Academic Failure. Eur J Psychol Educ. 2010;25(2):157-75.

14. Mesquita AC, Chaves ECL, Avelino CCV, Nogueira DA, Panzini RG, Carvalho EC. The use of Religious/ Spiritual Coping among Patients with Cancer Undergoing Chemotherapy Treatment. Rev. Latino-Am. Enfermagem. 2013;21(2):539-45.

15. Aguirre AA, Castillo MMA, Zanetti ACG. Adolescent Self-Steem and its Relationship to the Alcohol Risk Consumption. Rev. Latino-Am. Enfermagem. 2010;18(esp.):634-40.

16. Martins CR, Gordia AP, Silva DAS, Quadros TMB, Ferrari EP, Teixeira DM, et al. Insatisfação com a imagem corporal e fatores associados em universitários. Estud Psicol. 2012;17(2):241-6.

17. Rincón M.E, Pérez MA, Borda M, Martín A. Impacto de la reconstrucción mamaria sobre la autoestima y la imagen corporal en pacientes con cáncer de mama. Univ Psychol. 2012;11(1):25-41.

18. Mendes JA, Lustosa MA, Andrade MCM. Paciente terminal, família e equipe de saúde. Rev $\mathrm{SBPH}$. 2009;12(1):151-73. 
19. Campos MTFS. Uma influência do luto no comportamento alimentar e suas implicações

nas condutas nutricionais. Ciênc Saúde Coletiva.

2013;18(9):2769-79. 